IOSR Journal of Pharmacy

e-ISSN: 2250-3013, p-ISSN: 2319-4219, www.iosrphr.org

Volume 2 Issue 6 ||| Nov-Dec. 2012 ||| PP.29-35

\title{
A comparative analysis of dynamic lung parameters in IInd trimester of pregnancy
}

\author{
${ }^{1}$ Dr. Lata Gupta, ${ }^{2}$ Dr. R. Dixit, \\ ${ }^{I}$ Associate Professor Department of Physiology, G.M.E.R.S. Medical College, Sola, Ahmadabad. \\ ${ }^{2}$ Deputy Director - Medical Education Health, Medical Services and Medical \\ Education, 'G' Block, Civil Hospital, Gandhinagar. \\ Correspondence Address: \\ A - 61, Jupiter Towers/H Grand Bhagwati Hotel, Bodakdev, S.G. Highway, Ahmadabad-380054
}

\begin{abstract}
Pregnancy is principally a phenomenon of maternal adaptation to the increasing demands of the growing fetus1. Pregnancy causes many visible and invisible changes in human body and it represents one of the best examples of selective adaptation in terms of respiratory physiology.
\end{abstract}

AIMS: To evaluate the changes in dynamic pulmonary function tests (PFTs) in second trimesters of pregnancy and compare the results between normal pregnant women (case group) \& normal non pregnant women (control group) also comparing the results of the study with other studies.

DESIGN (MATERIAL \& METHOD):50 Subjects were divided into two groups, non pregnant women $(n=$ 20 , mean age $=26.5 \pm 2.69)$ and normal pregnant women's of second trimesters $(n=30$, mean age $=24.84 \pm$ 3.00). PFTs were done by medspiror.

RESULTS :Significant decrease in all the parameters of PFTs like Forced Vital Capacity (FVC), Forced Expiratory Volume in one second (FEV1), Peak Expiratory Flow Rate (PEFR), Maximum Ventilation Volume $(M V V)$, were seen in second trimester of normal pregnant women as compared to normal non pregnant women.

CONCLUSION: Out data suggests that there is alteration in PFTs in pregnant women. Continuous Monitoring of PFTs may prove to be of great value in maternal healthcare as cases of restriction and obstruction in lungs during pregnancy can be identified early and its deterioration can be prevented by proper management.

Keywords-PFTs, Pregnancy.

\section{INTRODUCTION}

Pregnancy causes many visible and invisible changes in human body. The highly efficient and sensitive respiratory system becomes vulnerable with profound changes during pregnancy where adaptability is a key feature to combat stress, anxiety and fear resulting in altered performance of systems to need demands ${ }^{1}$.

Pulmonary function tests (PFTS) permit an accurate and reproducible assessment of the functional state of respiratory system and allow quantification of the severity of disease.

Various investigators ${ }^{4,11}$ have studied pulmonary function tests (PFTS) during normal pregnancy but their results were conflicting. Out of various pulmonary function tests medspiror assess FVC, FEV1, PEFR, MVV, etc.

The scanty literature on pulmonary function testing during pregnancy has prompted the present work.

\section{MATERIAL AND METHODS}

About 50 subjects were examined for PFTs. In this linear study groups, 30 pregnant women were taken for case study and 20 normal female were examined for PFTs for control study. About 30 female pregnant patients belonging to the 20-30 yrs of age volunteered themselves for the present study belonging to middle socio economic status and come for regular check up in hospital as OPD basis. Young healthy normal non 
pregnant women of child bearing age (20-30 yrs) from medical faculty and also from those who accompanied the case subjects were selected for control group.

General physical examination of the subject including required anthropometric measures such, as height, weight and chest circumference was noted. Resting body temperature resting pulse rate, and Blood Pressure were taken in sitting postured after half an hour of rest for every time when they come for pulmonary function testing.

Anthropometric measures such as height, weight was noted. In standing posture, during late morning session, after taking consent and explained the procedure to the subjects and they were asked to take maximum deep inspiration then blow out with maximum effort in mouth piece of medspiror which already apposed between the lips firmly. Nose was closed by nose clips. As two reading for PFTs were taken on instrument and the highest one selected for calculation.

The instrument was fed with the data, height in centimeters age in years, weight in Kilograms, sex and room temperature prior to performance of a FVC maneuver. The specifications of Instrument provides flow rate $\mathrm{L} / \mathrm{Sec}$ versus volume (L) plot and provides volume verses time plot recordings on thermo sensitive paper.

Results of PFTs displayed and recorded as follows :

FVC - Forced Vital Capacity

FEV1 - Forced Expiratory Volume in one second

PEFR - Peak Expiratory Flow Rate

MVV - Maximum Ventilation Volume

RR - Respiratory Rate

The actual values as measured during the maneuvers, predicted values for the specific patient, when compared to others of same age, height, sex or percentage predicted values, i.e. a ratio of actual value and predicted value expressed as percentage are displayed and if resources available printed records can be obtained. The PFTs data's are examined by medspiror and a diagnosis of obstructive or restrictive disease is made and there are a number of systems which used to determine the severity of disease. Here is just one way that is very commonly used ${ }^{11}$.

$\begin{array}{lll}\text { Normal PFT outcomes } & : & >85 \% \text { of predicted values } \\ \text { Mild Disease } & : & >65 \% \text { but }<85 \% \text { of predicted values } \\ \text { Moderate Disease } & : & >50 \% \text { but }<65 \% \text { of predicted values } \\ \text { Severe Disease } & : & <50 \% \text { of predicted values }\end{array}$

If both FVC and FEV1 are normal, then patient has a normal PFT tests. If FVC and/or FEV1, is 80-90 $\%$ or higher, then patient has restricted lung disease. If the \% predicted for FEV1/FVC is $69 \%$ or lower, then the patient has an obstructed lung disease.

\section{RESULTS AND OBSERVATION}

Statistical analysis was done for all parameters undertaken in study along with some investigative parameters. The age ranged between 20-30 yrs in both groups.

The figures of range have been rounded off, second trimester pregnant women are abbreviated as Case in tables \& graphs. Percentage difference (\% diff) for increase or decrease in any parameter was calculated, considering the mean values of controls (non pregnant subjects) as baseline when compared with the case group (IInd trimesters). 
TABLE - 1

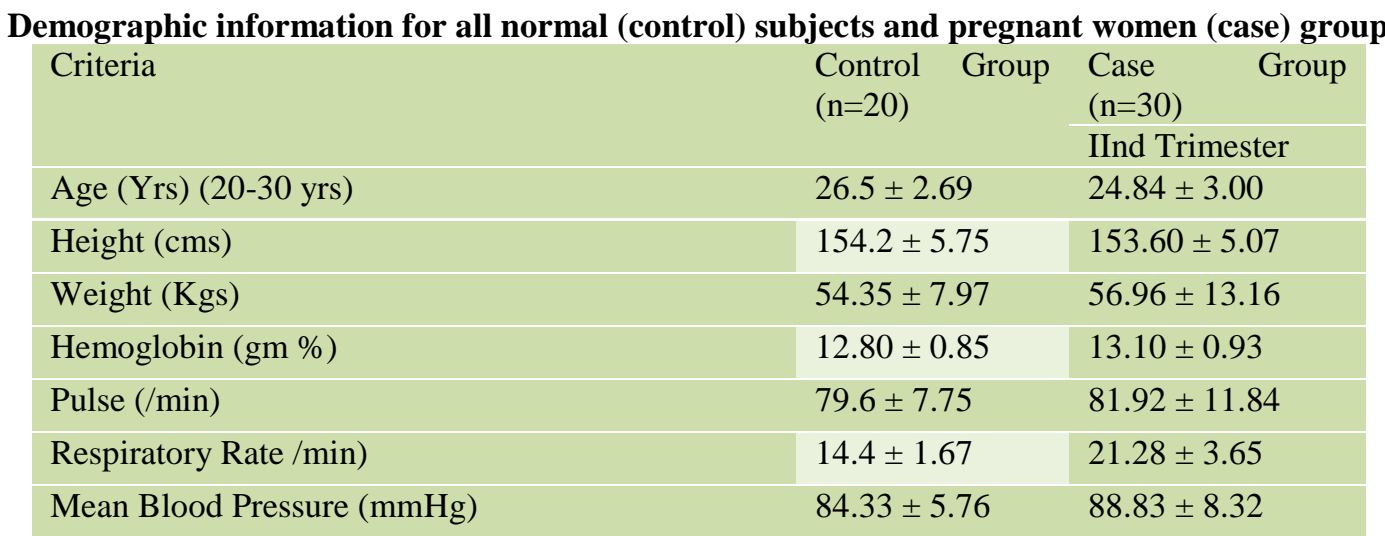

Table-1 shows the demographic information of all normal control and case group. The age ranged between 20$30 \mathrm{yrs}$ in both groups. The table shows weight $(\mathrm{Kgs})$, height $(\mathrm{cms})$ and also hemoglobin levels estimated by Sahli's Acid Haemetin Method and was found to be within normal limits. Mean Blood Pressure also lies within normal limits for both control and case group.

TABLE - 2

Mean pulmonary function tests (pfts) datas in normal control group

\begin{tabular}{|l|l|l|}
\hline \multirow{2}{*}{ Criteria (Lt / Sec.) } & Control Group $(\mathrm{n}=20)$ \\
\hline RR & Actual & \% Predicted \\
\hline FVC & $14.4 \pm 1.67$ & $21.28 \pm 3.65$ \\
\hline FEV1 & $2.133 \pm 0.21$ & $91.9 \pm 10.77$ \\
\hline PEFR & $1.96 \pm 0.23$ & $1.90 \pm 0.15$ \\
\hline MVV & $5.39 \pm 0.55$ & $86.2 \pm 7.15$ \\
\hline
\end{tabular}

Unpaired 't' test by OS 3 programme (computer), was done to find the level of significance as number of control subjects is differ from the number of case group.

Respiratory parameters shows significant changes when third trimester values of case group were compared with non pregnant state (Control group).

The calculated' values and corresponding 'p' values are given for various sample groups for all the respiratory parameters.

TABLE - 3

Statistical analysis for forced vital capacity (lt/sec.)In normal control group and in second trimester of pregnancy

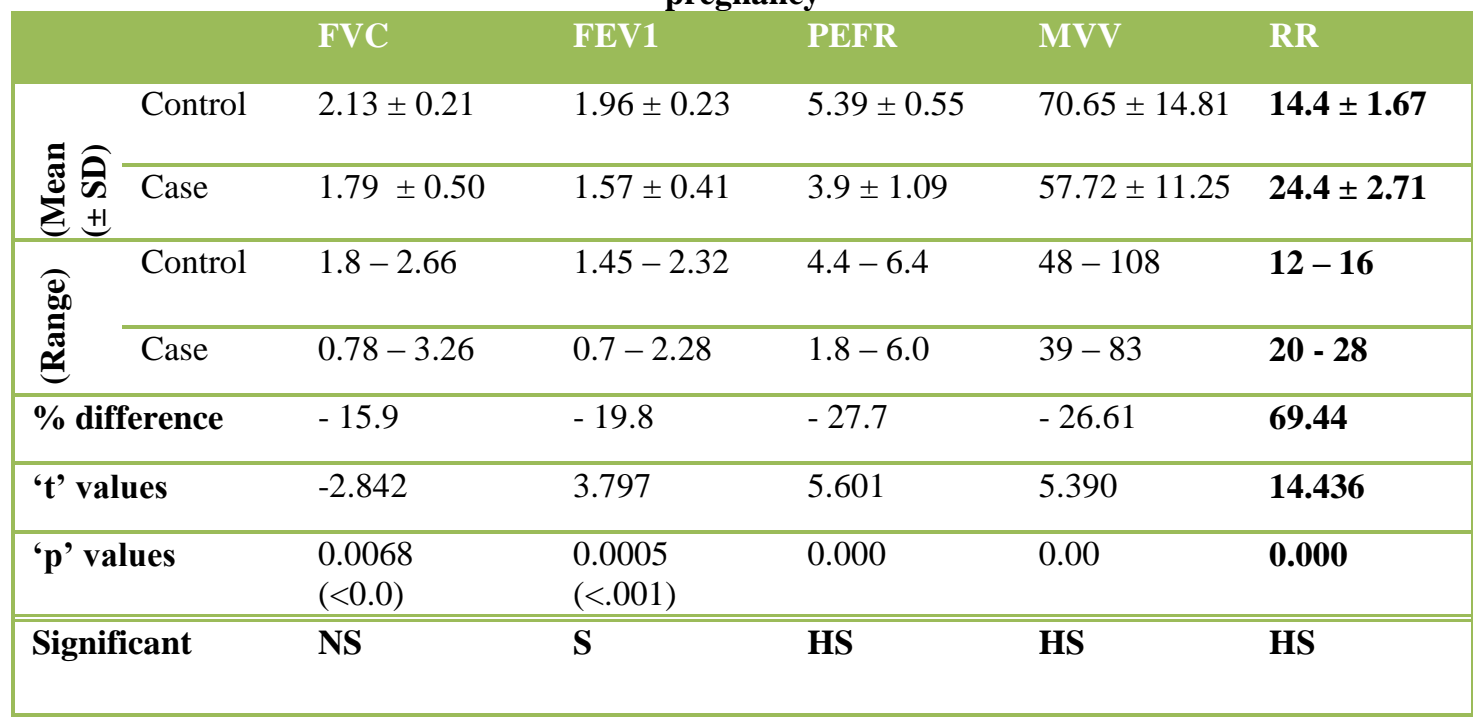


Graphical representation of pfts (It/sec.) In control group and comparision with IInd - trimester of pregnancy.
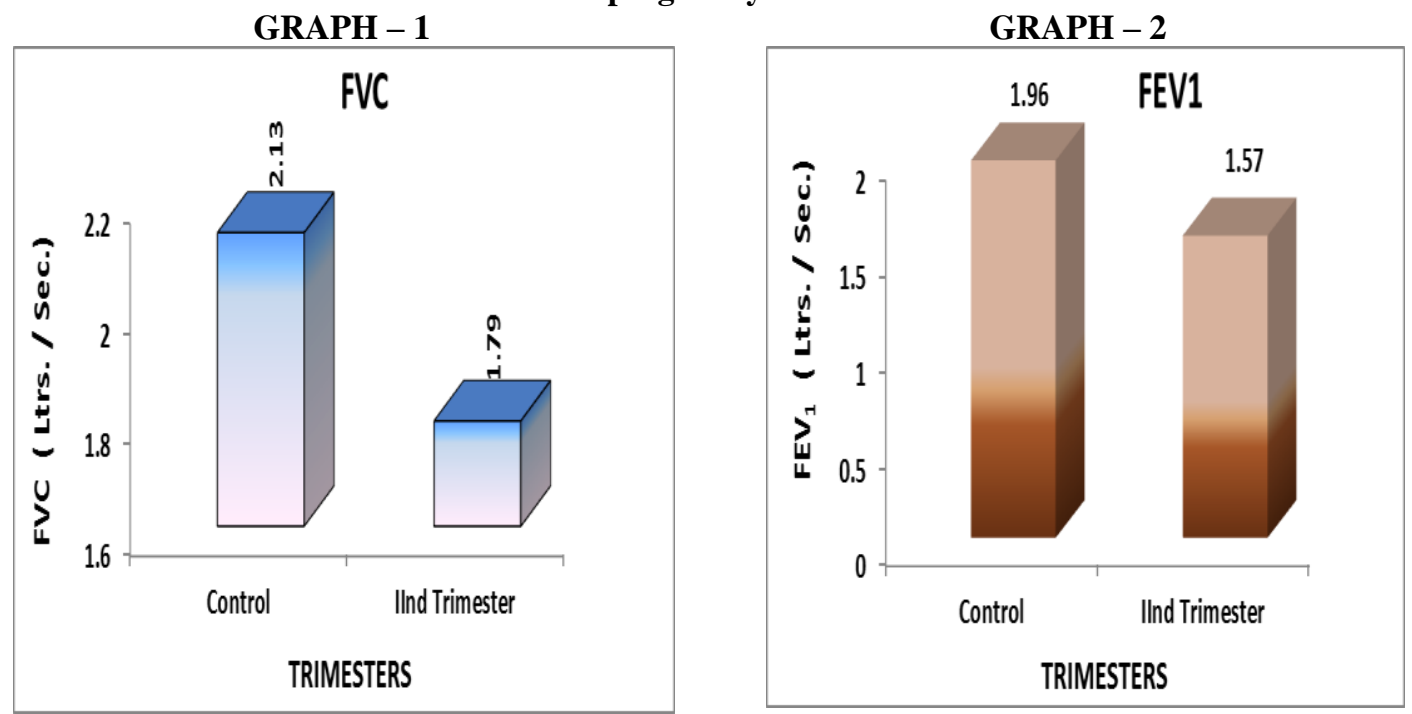

GRAPH - 3

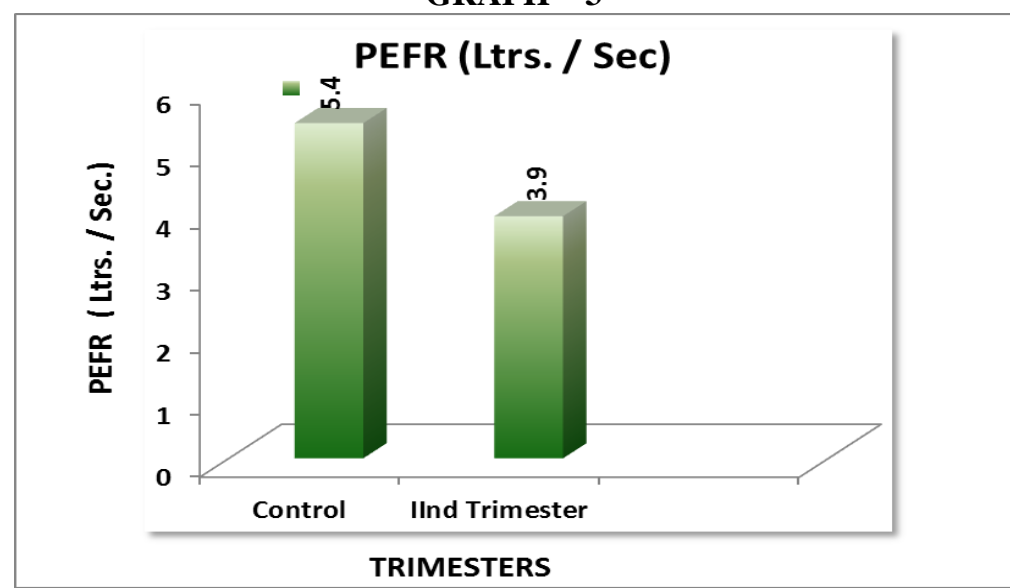

GRAPH -4

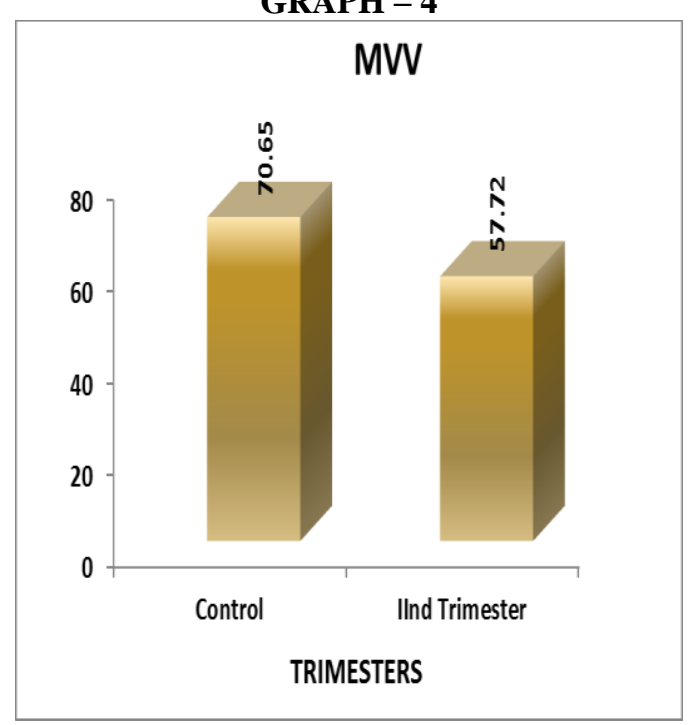

GRAPH - 5

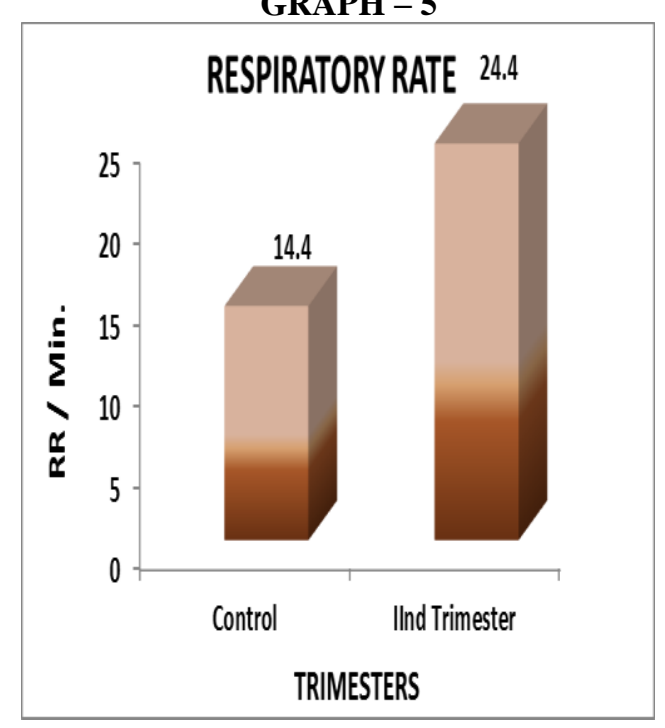


GRAPH - 6

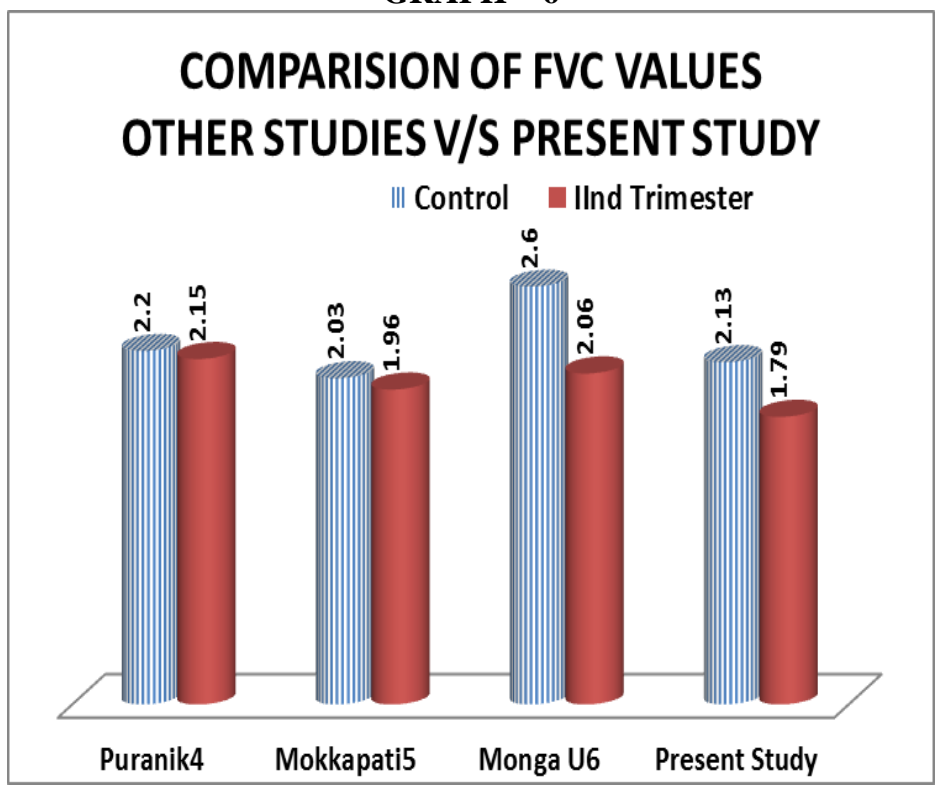

GRAPH - 7

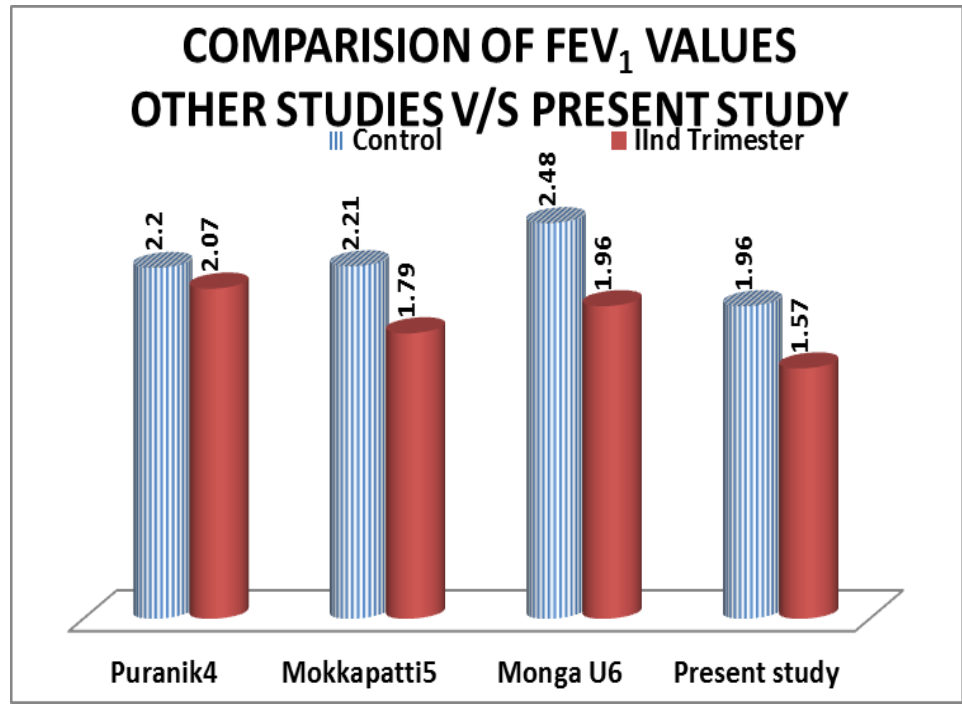

GRAPH - 8

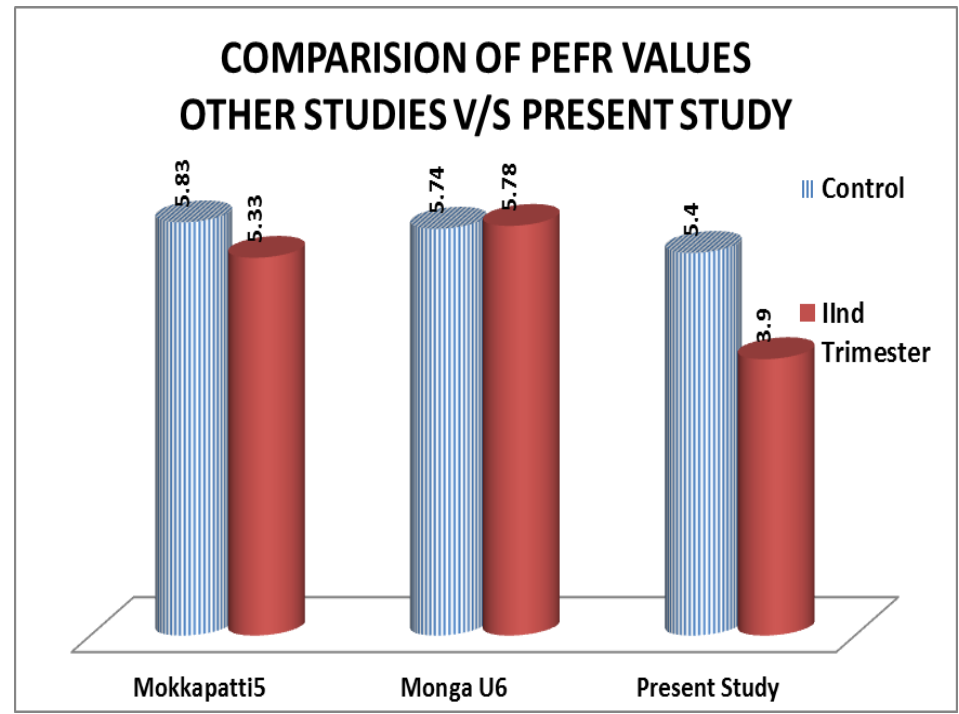




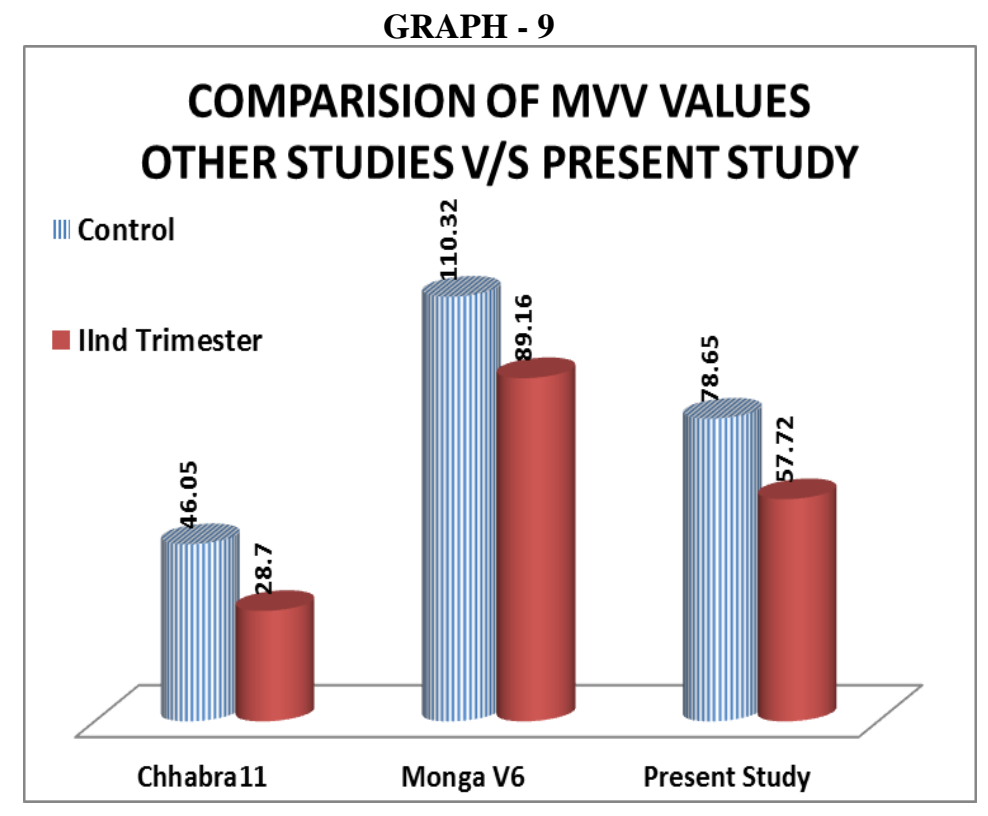

\section{DISCUSSION}

- PFTs were conducted with the help of medspiror.

- All the results were statistically analyzed.

- The results of PFTs parameters are briefly tabulated in table 1, 2, 3 for inferring the changes that have occurred at glance and compared with various studies that have already published.

- Some studies ${ }^{3}$ shows significant rise in FVC. Mostly all studies ${ }^{4,5,6}$ show decrease in FVC.

- Significant reduction in FVC may be obtained due to restrictive effect of the enlarging uterus ${ }^{4}$.

- FVC is diminishing due to augmentation of rib cage volume displacement, relative mobility of thoracic cage and unimpaired diaphragmatic movements ${ }^{4}$.

- FEV1 is essential to access ventilatory capacity of the pulmonary or to access the ability to ventilate ${ }^{2}$.

- A number of studies ${ }^{4,6,8,9}$ as reviewed show decrease in FEV1.

- No change in FEV1 seen in few studies ${ }^{3,5}$.

- Decline in FVC and FEV1 due to mechanical pressure of enlarging gravid uterus, elevating the diaphragm and restricting movements of lungs ${ }^{4,6,9}$ and thus hampering the forceful expiration.

- It may also be due to bronchoconstrict effect of decreased aveolar $\mathrm{PCO}_{2}$ on the bronchial smooth muscles ${ }^{3,6}$.

- All studies ${ }^{5,6}$ shows statistically significant, decline in PEFR.

- The restriction brought about by enlarged breast growing gravid and the fear of complications arising at term due to abdominal pressure required to forcefully inspire and expire for executing flow rates could render lowered values during pregnancy. The mechanical effects of gravid uterus cause relatively adaptive changes in pulmonary mechanics ${ }^{10}$.

- All studies ${ }^{6,11}$ show significant decline in mean values of MVV.

- MVV decrease during pregnancy indicating of a mechanical inhibition of chest ${ }^{4}$.

- The decrease MVV may also be attributed to an increased oxygen per unit of work done in the respiratory muscles scar.

\section{CONCLUSION}

In control subjects, pulmonary function tests by medspiror were within normal range.

In IInd trimester of normal pregnant cases, pulmonary function tests were seen lower as compared to normal non pregnant state.

FEV1, FVC decrease in pregnant case group providing that pregnancy is a restrictive condition and not obstructive, the decrease in values of these parameters also suggests that dysfunction of expiratory muscle is not there though weakness may be there and mechanical properties of respiratory system are normal that are due to altered configuration affecting elastic recoil of chest and intra thoracic diameter.

Peak Expiratory Flow Rate (PEFR) decreases states that it might be caused by upward displacement of diaphragm, reduced strength of expiratory muscles and mechanical effect of growing uterus. 
Other factors as morning sickness, lack of motivation and resistance to exertion contribute in decreasing Maximum Ventilation Volume (MVV).

Because of abdominal distension, there is gradually fall in all pulmonary function tests values.

The importance of continuous antenatal surveillance and therefore use of pulmonary function test by medspiror is thus evident in early identification of suspected and established cases of restriction and obstruction in lungs during pregnancy. The disease can be identified early and its deterioration can be prevented by proper management.

\section{REFERENCE}

[1]. Dutta DC - Physiological Changes during Pregnancy. In : Text Book of Obstetrics and Gynecology, 4th Edi. Calcutta: New Central Book Agency, 1998 : 46-57.

[2]. Cotes JE - Lung Function assessment and application in medicine: 3rd Edi. Oxford: Black well scientific publications, 1975 : 93-105.

[3]. Milne JA, Mills RJ, Howie AD and Pack AI - Large airways function during normal pregnancy. Br. Jr. of Obst. and Gynaec 1977; $84: 448$ - 451.

[4]. Puranik BM, Kaore SB, Korhade GA, Agrawal SD, Patwardhan SA and Kher JR - A longitudinal study of pulmonary function tests during pregnancy. Indian J. Physiol Pharmacol 1994; 38(2) : 129 - 132.

[5]. Mokkapatti R, Prasad EC, Venkatraman, and Fatima K - Ventilation functions in pregnancy. Indian J. Physiol and Pharmacol 1991; 34(4) : 237 - 249.

[6]. Monga U and Kumar K - Pulmonary functions in Punjabi Pregnant Women. Indian, J. Physiol Pharmacol 2000; 44(1) : 115-16.

[7]. Sheikh AM, Deshpande DR, Ganeriwal SK and Reddy BV - Effect of Pregnancy on Vital Capacity and FEV1. J. Obst. and Gynaec India 1983; $33: 495$ - 499.

[8]. Phatak MS and Kurhade GA - A longitudinal study of Antenatal changes in lung function tests and importance of post parted exercise in their recovery. Indian J. Physiol, Pharmacol 2003; 47(3) : 352 - 356.

[9]. Pandya MR, Nishith SD and Bhatt RV - Pulmonary function in pregnancy. J. Obst. and Gynaec India, 1972; 22(1) $: 1-3$

[10]. Fishman AP - The Lung in Pregnancy. In: Fishman's Editors - Pulmonary Disease and Disorders. 3rd Ed, New York : Mc Graw Hill Inc, $1998: 243$ - 251.

[11]. Chhabra S, Nangia V and Ingla KW - Changes in Respiratory Function Tests during Pregnancy. Jr. of Physiol and Pharmacol 1987; 32 (1) : 56-60.

[12]. Gupta L, Dixit R - Study of Pulmonary Function Tests (PFTs) in Normal Pregnant Women of Third Trimester. Indian Medical Journal, 2011; 105(2): $67-70$.

[13]. Gupta Lata, Dixit R - Evaluation of pulmonary function tests in normal pregnant (II \& III trimester) \& non pregnant women. I.J.A.B.M.S., $2012 ; 14$ B (19). 